\title{
Technology Education for the 21st Century in Australia?
}

Investigating Effective Practice in Schools

\author{
C. Paul Newhouse
}

School of Education, Edith Cowan University, Perth, Western Australia

p.newhouse@cowan.edu.au

Keywords: computing, curriculum changes, curriculum policies.

\begin{abstract}
This paper reports on recent research to investigate effective practice and develop a definition of quality technology education in Australian primary and secondary schools. In Australia technology education encompasses a range of practical subject disciplines including working with materials, fabrics, food and media, and the provision of computer (ICT) education. The study developed a theoretical model of quality and effective practice that was used to describe the technology education provided by a selection of leading schools. A number of major issues were identified and recommendations were developed. In particular, many schools needed substantially more equipment, materials and teacher training and the 'optional' status of technology education in the compulsory years of education needed to be removed.
\end{abstract}

\section{INTRODUCTION}

During the late 1990s technology education policy and practice in Australian school systems has been undergoing a gradual revolution. In policy documents technology education has been recognised as an important area of learning in the same way that mathematics and language are so recognised. At the same time it has been recognised that the types of experiences students need are different to those of students in the 1950s and 1960s, the era from which traditional technology education courses have emanated. There is a need to clearly define quality technology education and suggest strategies to encourage effective practice in schools. 
This paper reports on the outcomes of a component of a study that aimed to analyse effective practice and develop a definition of quality technology education in Australian primary and secondary schools.

\section{METHODOLOGY}

The component study employed two main methodologies. The first was a literature search to develop a model for a definition of quality technology education and effective practice in schools. The second used a series of case studies of leading sites throughout Australia to verifying and modify the model. The review of literature continued throughout the project but was particularly intense at the beginning.

It was planned to have at least three leading sites in each state to cover primary and secondary schools, regional schools, government and nongovernment schools. Each leading site was visited by a researcher for at least one day in order to collect data that included observation of facilities, interviews with school personnel, and questionnaires for samples of students and teachers. The observational schedule focused on whole school-level rather than classroom level features and was concerned with curriculum implementation and support at a school site. The interview schedules focused on classroom level features and was concerned with the implemented curriculum and teacher attitudes, understandings and beliefs.

\section{THEORETICAL MODEL}

The theoretical model of quality and effective practice in technology education was based on literature, particularly from Europe (principally United Kingdom), the United States of America, New Zealand and Australia. It was presented as a concept map (this may be accessed at http://edresearch.ed.ac.cowan.edu.au/paul/technology/) with a discussion paper outlining the features on the concept map. At the centre of the model are the concepts "Quality Technology Education" and "Effective Practice".

Quality Technology Education in a school is fundamentally represented by the learning outcomes achieved by the school's programmes. Quality is based on the attainment of valued outcomes with students that in technology education will concern technological capability. Kimbell (1994) and others see the concept of "active technological capability" as the fundamental goal of technology in schools" (p. 1). The concept concerns students doing rather than simply knowing about. It encompasses a view of the world that perceives technology as a means of transforming the natural world to satisfy 
some human need. In outcomes-based education assessment of technological capability will be based on the judgements made by teachers. However, clearly this will also be evidenced by the perceptions of students. The project did not attempt to measure learning outcomes, rather they were implied within the definition of effective practice expounded within the model.

Effective Practice contributes to Quality Technology Education and is evidenced by features of a number of aspects of the school's programmes. Effective practice as filtered by pedagogical philosophy will be evidenced by a number of constructs associated with schooling. These constructs, based on the findings of relevant international research, were represented in the concept diagram: the intended curriculum, the implemented curriculum, instructional methodology, assessment practices, and the facilities and equipment available. Each of these constructs is supported by a number of observable features also represented in the concept diagram. These observable features are discussed below and formed the basic framework for reporting on data collected from schools.

\subsection{Judgements of teachers}

Assessment under an outcomes-based system is dependent on teachers making judgements about the level of a student's technological capability based on what students do and say. This is stated in most Australian system curriculum statements and will involve making judgements about students' understanding of concepts, their level of technology skill (e.g. process skills, manipulative skills), and their attitudes towards technology. Unfortunately the limited conception of technology and the lack of understanding, knowledge and confidence of primary school teachers in the area of technology education (Australian Science Technology and Engineering Council 1997) will make it difficult for them to make these judgements.

\subsection{Perceptions and conceptions of students}

Students perceptions and conceptions of technology have a major impact on their technological practice, perhaps even more than teaching strategies (Jones 1997). Typically students while having a positive attitude have a limited concept of technology. Broader views of technology allow students to undertake activities in a holistic fashion in terms of the processes they use (Jones 1997). Clearly for older students their perceptions of the role of technology in the workplace, particularly as related to potential careers is important. However, for all students the perception of personal use of technology will influence their attitude towards learning activities at school. This has been particularly relevant for computer technology. 


\subsection{The intended curriculum}

The intended curriculum is that laid down by educational systems or authorities to which teachers must adhere. Typically this is defined formally in documents variously labelled curriculum frameworks and syllabus statements. These are often supported by resource materials and informal understandings communicated through policy or practice forums. In Australia a national curriculum framework was developed in the early 1990s (Curriculum Corporation 1994). Most states also have a comprehensive curriculum framework such as that in place in Western Australia (Curriculum Council of Western Australia 1998). These frameworks support the importance of technology education and support its proper implementation.

\subsection{The implemented curriculum}

The implemented curriculum is that instituted within a school by teachers for students based on the intended curriculum. A recent Australian study found a disparity between the official support for technology education and "that which occurs in practice" (Australian Science Technology and Engineering Council 1997, p. 1) with particularly little emphasis at the primary school level. If the implemented curriculum is to provide opportunities for the development of technological capability then it will need to provide appropriate activities with supporting facilities and equipment, consider equity and progression, and provide a breadth of technological activity.

Students should actively work with a range of technologies (Todd 1997) that are appropriate to their present and perceived future needs and to support their interests. There is a danger that in an attempt to provide the infrastructure to support a range of technologies within budget limitations that schools provide facilities and equipment which do not allow for authentic contexts for activities.

The curriculum must make provision for equity and progression. All students should also be provided with a technology education that allows for a progression of experience and is integrated with the rest of their curriculum. Central to learning are the experiences or activities that students engage with. These must challenge and interest them while being realistic contexts(Jones 1997). Kimbell (1996) suggests that contexts of tasks need to be real and that students be provided with activities that vary in their entry points from highly contextualised to highly particularised. 


\subsection{Instructional methodology}

Technology education fundamentally concerns the application of process with the development of conceptual knowledge (McCormick 1996). It involves processes of design, problem-solving and investigation in the application of independent bodies of knowledge and skills to holistic activities (Jones 1997).

The technology process involves students in investigating, designing, making, and evaluating products, processes, systems, environments and services. The aim is to meet human need through enhancing the environment. The central processes involve design and problem-solving. The process of technology is not a rigid set of specific tasks (McCormick 1996), but varies depending on the nature of the activity, the prior experience of the students, and the outcome goals the teacher would like the students to achieve.

Problem-solving is defined by Todd (1997) as "a structured component within a general investigative approach to learning" (p. 207) and it implies that there is a problem to solve. While much of the conceptual knowledge base required by students relies on other curriculum areas technology education should contribute to the development of such conceptual knowledge. This can be accomplished by allowing students to generalise through working in a number of different contexts. Specific knowledge is developed on a need to know basis (McCormick 1996).

Students work independently and in shared situations at various stages in the technology process. It is important for students to regularly experience collaborative work in technology activity both from the point of view of promoting learning and to replicate workplace requirements (McCormick 1996). Students need to experience working with each other with technology, not just on isolated group-work activities, but as part of many parts of the Technology Process such that they share goal-setting, creating designs and the production of technologies.

The role of performance on skills in technological capability is a contentious issue that has normally focused on assessment of practical skills (Lewis 1999). The Technology Process approach requires students to develop skills in critical thinking, decision-making, information processing, modelling and general problem-solving (Levande et al. 1998). As they encounter a range of technologies students will need to develop skills in their use and application when they are needed within activities. 


\subsection{Assessment practices}

Many authors and reports link the technological literacy rationale with a need for standards and assessment. It is argued that these will raise the low status of the area by establishing high expectations and provide an impetus for improvement of teachers and learning environments (International Technology Education Association 1996). Where there is an emphasis on summative assessment students are likely to devalue the processes and principles involved in their activities (Jones 1997). Assessment should be used by teachers, administrators and educational leaders to plan future programmes. Assessment activity in technology education must encompass a full view of the principles, particularly associated with the Technology Process, which lends itself to portfolio assessment (Levande et al. 1998).

\section{ISSUES ARISING}

The following issues arose from an analysis of the data collected from the leading sites (schools). Specific data can't be provided due to confidentiality requirements.

\subsection{The low status of technology education}

While it is clear that in the eyes of teachers and school administrators technology education is being afforded the status of a learning area separate from science or mathematics it still has to fight to be treated as being of relatively equal importance. Typically technology education has been an 'elective' area in secondary schools and a 'new' area or a peripheral area to science in primary schools. One of the primary school principals commented that a problem was the "weak perceptions held by parents of the Learning Area - apparently there exists the view that Technology is 'play' and not serious education." In addition there is little requirement for study in technology education for post-secondary destinations, and there is no clear definition or requirement for technological literacy. Even in primary/early childhood environments it is often viewed as a luxury as compared with central importance of numeracy and language literacy.

Strong support from the Principal is required to implement an effective technology education programme. To change the perceived low status of the area typically requires specific initiatives that have serious budgetary and policy implications and therefore require the support of the Principal. In most leading sites the Principal not only supported the learning area but was able to clearly explain the nature and aims of the area. Principals often 
provide support for the professional development of teachers if they possess an understanding and empathy for the learning area.

\subsection{The balance between vocational and general educational aims}

Traditionally the aims of technology education have mainly focussed on developing skills for the workplace or more recently home living requirements, vocational aims. During the past decade the curriculum emphasis has moved towards the more general educational aims concerning the development of awareness, conceptual understanding, and considering the broader issues of using technology in society. This balance between vocational and general educational aims tends to be mirrored in the balance between product and process with vocational aims associated with concentration on the development of skills in high quality production. The balance between these two sets of aims has implications for the range of technologies made available and the type and quality of equipment and materials provided in secondary schools.

A number of the selected schools had developed an approach to technology education which used it as the vehicle for broader aims of curriculum integration and/or the introduction of an outcomes-based approach to education. This improved the status of the area and encouraged teachers to invest in the implementation of technology education and, at the secondary level, move away from the traditional vocational-product approach to technology. Many of the selected schools found that concentrating on a new area such as technology education which was well suited to an outcomes-based approach helped induct teachers and school communities into the approach.

\subsection{Providing a range of technologies and materials}

The range of technologies and materials available for students at a school, particularly primary school, depended a lot on the expertise and enthusiasm of teachers and the costs of providing adequate access. All schools had increased their provision for computer technology. Leading secondary sites tended to aim to provide a range of technologies which focussed more on newer or 'lighter' technologies such as microwave food technology, power-tools for wood and metal, multimedia and control technologies. In primary schools there was an enthusiasm for introducing as wide a range of technologies as possible, often starting with computer- 
related technologies and then wood-related technologies (typically handtools and some power-tools).

Since much of technology education provides new content for Primary programmes few schools have the resources to provide adequate experience for students other than with craft type materials. A limitation for most schools is the lack of adequate room-space to conduct production with equipment needing to be taken into cluttered regular classrooms giving rise to safety concerns. A further problem in primary schools was the lack of experience and training in the area of most teachers (predominantly female). They lack competence and confidence in using basic hand and power tools used with materials such as wood, metals, electronics and plastics. As schools purchase such equipment it will either be used inefficiently or dangerously. There is a need for primary schools to have a designated coordinator for technology education to encourage progression of learning experiences.

Most components of technology education at all levels of schooling suffer from a lack of technical support persons with teachers being required to complete many maintenance and installation procedures. Given the equipment and materials intensity of the learning area it is difficult, particularly in secondary schools, to comprehend this when compared with the support traditionally given to the science learning area. This was a problem for most government school leading sites and some nongovernment schools.

\subsection{The place of computing (IT)}

There has been increased confusion concerning the role of computing in technology education since the term 'learning technologies' has become almost synonymous with using computers to support learning. The complexity of the relationship between technology education and the use of computers has led to serious levels of confusion among teachers, parents and educational leaders. There are extreme attitudes from "computers are not a part of technology education" through to an equation between computers and technology education. In many schools (including some of the leading sites) the leader of computing is also the leader for learning technologies which adds to this confusion. Within technology education it is legitimate to focus on computers as an area of study where students will learn about computer technologies, how to use them and their place within society. Computers may also be used as a learning tool but this is a different issue. All the leading sites had developed significant computing resources and most provided comprehensive learning programmes in computer technology. Computers were also used to support many technology processes and were 
used as learning technologies in many learning areas, including technology education.

\section{CONCLUSIONS}

The study generated a number of recommendations. Primary schools needed substantially more equipment, materials and teacher training to provide effective technology education. The 'optional' status of technology education in the compulsory years of secondary education needed to be removed and replaced with a minimum requirement such as that which exists for mathematics, English language and science. The Universities needed to be encouraged to free up rules for entry and accept studies in technology. The leadership roles in schools for Technology Education needed to be separated from that of Learning Technologies. All schools needed to be provided with adequate technical support for the range of technologies made available to students. Primary school facilities needed upgrading to include a purpose-built area for technology with appropriate equipment, storage and professional development for teachers. Clearly there is still much to be done to provide all Australian children with a high quality technology education.

\section{REFERENCES}

Australian Science Technology and Engineering Council (1997) Foundations for Australia's Future: Science and Technology in Primary Schools. Report, Department of Industry, Science and Tourism, Canberra.

Curriculum Corporation (1994) A statement on technology for Australian schools. Carlton: Curriculum Corporation.

Curriculum Council of Western Australia (1998) Curriculum Framework for Kindergarten to Year 12 Education in Western Australia. Curriculum Council of Western Australia, Perth

International Technology Education Association (1996) Technology for All Americans: A Rationale and Structure for the Study of Technology. Report, International Technology Education Association, Reston, Virginia.

Jones, A. (1997) Recent research in learning technological concepts and processes. International Journal of Technology and Design Education, 7, pp. 83-96.

Kimbell, R. (1994) Technological capability and its assessment in the UK National Curriculum. In Australian Council for Education through Technology, Hobart, Tasmania.

Kimbell, R. (1996) Technology tasks and pupils' learning. In Technology Education for Teachers, J. Williams and A. Williams (Eds.), MacMillan Education Australia Pty Ltd., Melbourne, pp. 93-110.

Levande, J. S., Glaser, R., Henrion, A., Kruyer, R., Schmitt, L. and Woodman, D. (1998, April) Technology education initiatives and statewide curriculum integration in Michigan. Paper presented at the Annual Meeting of the International Technology Education Association, Fort Worth, Texas. 
Lewis, T. (1999) Research in technology education - some areas of need. Journal of Technology Education, 10 (2).

McCormick, R. (1996) Instructional methodology. In Technology Education for Teachers, J. Williams and A. Williams (Eds.), MacMillan Education Australia Pty Ltd., Melbourne, pp. 63-92.

Todd, R. D. (Ed.) (1997) A new paradigm for schooling. (46 ed.), McGraw-Hill, New York.

\section{BIOGRAPHY}

I have always considered myself to be both an educator and learner in all aspects of my life. For nine years this was largely realised in an innovative state secondary school in Western Australia where I had the opportunity to put into practice a range of philosophically based programmes and strategies in teaching across the curriculum. Since then I have had the privilege of sharing my experiences with pre-service and practicing teachers for over ten years in two universities. My current appointment is as a lecturer with the School of Education at Edith Cowan University. 